\title{
Stentoplasty with Resorbable Calcium Salt Bone Void Fillers for the Treatment of Vertebral Compression Fracture: Evaluation After 3 Years
}

\author{
Mengmeng Chen (D) \\ Ruideng Wang \\ $\mathrm{Pu}$ Jia \\ Li Bao \\ Hai Tang (D)
}

Department of Orthopaedics, Beijing Friendship Hospital, Capital Medical University, Beijing, People's Republic of China
Correspondence: Hai Tang Department of Orthopaedics, Beijing Friendship Hospital, Capital Medical University, No. 95, Yong an Road, XiCheng District, Beijing, I00050,

People's Republic of China

Tel +86I360 I362187

Email tanghai@ccmu.edu.cn
Purpose: The aim of the study is to investigate the clinical and radiological outcomes of vertebral compression fractures treated by stentoplasty with resorbable calcium salt bone void fillers compared with balloon kyphoplasty (BKP).

Methods: This prospective study included patients with fresh mono-thoracolumbar vertebral compression fractures. Patients enrolled were randomly divided into three groups. The patients in group A underwent stentoplasty with calcium sulfate/calcium phosphate (CSCP) composite filler and patients in group B with hydroxyapatite/collagen (HAP/COL) composite filler, while patients in group $\mathrm{C}$ underwent BKP with polymethylmethacrylate (PMMA). The clinical outcome was evaluated with visual analogue pain scale (VAS) and Oswestry disability score (ODI). The radiological results were evaluated with anterior height $(\mathrm{AH})$ and Cobb angle of vertebral body. Computed tomography (CT) was used to assess osteogenesis effect.

Results: Each group included 14 patients. The VAS, ODI, Cobb angle and AH were statistically improved compared with preoperative and there was no significant difference between the three groups. However, the AH in group A and group B at 1-year follow-up presented slight loss compared with 1 day after surgery. CT results suggested both group $\mathrm{A}$ and group B presented obvious bone trabecula formation and variations of $\mathrm{CT}$ value.

Conclusion: The stentoplasty with resorbable calcium salt bone void fillers demonstrated clinical outcomes similar to traditional BKP for vertebral compression fractures. Both HAP/ COL and CSCP performed certain osteogenesis. However, stentoplasty with studied fillers showed slight loss of AH within 1 year after surgery.

Keywords: stentoplasty, vertebral compression fracture, filler material, bone fillers, osteogenesis

\section{Introduction}

Vertebroplasty (VP) was first described by Galibert et al. in vertebral angiomas. ${ }^{1}$ In the last three decades, VP has been used extensively to treat osteoporotic and malignant vertebral compression fractures. Injection of polymethylmethacrylate (PMMA) bone cements aims to achieve the restoration of vertebral body height and eliminate the pain caused by fractures or tumors. However, bone cement leakage is the most common complication which may result in radicular pain, paralysis and even death. ${ }^{2-4}$ Balloon kyphoplasty (BKP) was designed to reduce the pressure of infusion and the risk of bone cement leakage. ${ }^{5,6}$ In consideration of the loss of vertebral body height after balloon withdrawal in BKP, stentoplasty was 
developed. Vertebral body stenting (VBS), using an inflatable balloon for expansion, has been proved to achieve a satisfactory reduction and maintain the restored vertebral height after balloon withdrawal. ${ }^{7,8}$ In recent years, a new minimally invasive technique, called Stent-Screw Assisted Internal Fixation (SAIF), was developed based on the VBS system and can be applied in severe neoplastic and osteoporotic fractures. ${ }^{9,10}$ It has good clinical efficacy and biomechanical support. ${ }^{11,12}$ The VBS/PMMA can effectively reconstruct the load-bearing capacity of the anterior column. The screw anchoring to the vertebral pedicle bridged with VBS/PMMA complex avoids bone cement displacement and reduces the stress distribution of the surrounding structure. ${ }^{11}$ However, the application of VBS and PMMA may increase the operative vertebral stiffness.

PMMA can provide main stability due to its microinterlocking with the surrounding bone trabecular. However, PMMA has disadvantages such as high polymerization temperature, ${ }^{13}$ potential cytotoxicity, ${ }^{14}$ poor biocompatibility and no biodegradation, ${ }^{15}$ which could cause complications such as cement leakage, osteonecrosis in the vertebral body, and fractures in the adjacent vertebral body. In histopathology, we can observe fibrous membrane formation between PMMA and bone trabecular without any remodeling process. ${ }^{16}$

Calcium phosphate cements (CPCs) can be considered as an alternative bioactive bone filler to PMMA. The application of CPCs as filler in vertebral compression fractures is still controversial. Some investigators reported favorable clinical results for CPCs used in vertebra fractures. $^{17,18}$ However, several literatures emphasized that standalone CPCs are prone to vertebral body refractures. ${ }^{19,20}$ Undoubtedly, the mechanical properties of CPCs are inferior to PMMA. ${ }^{21}$ Schutzenberger et al. performed stentoplasty with CPCs to treat vertebral fracture which showed excellent clinical results, but height loss still existed. ${ }^{22}$ The major disadvantage of CPCs is longer osteogenesis time and resulting weaker stiffness. In order to improve mechanical strength, two different methods are proposed: one is to improve primary stabilization through adding fiber reinforcements; and the other is to build secondary stabilization with callous tissue of new bone rapid formation. ${ }^{21}$

In recent years, there are several new calcium salt bone void fillers that have been adopted in orthopedics and craniomaxillofacial surgery, such as calcium sulfate/calcium phosphate (CSCP) composite and hydroxyapatite/ collagen (HAP/COL) composite. $^{23,24}$ Both have demonstrated good bioactive properties, which have been confirmed in fast osteogenesis. ${ }^{25,26}$ However, studies of these fillers used in stentoplasty are rarely reported.

Therefore, we designed a prospective study to investigate stentoplasty with resorbable bone fillers to treat vertebral compression fractures. Our aim was to clarify the clinical and radiological outcomes of vertebral compression fractures treated by stentoplasty with resorbable calcium salt bone fillers compared with traditional BKP.

\section{Methods}

This study was approved by the life ethics committee of Beijing Friendship Hospital and was registered in China clinical research and trial center (ChiCTR-OIC -16008922). We confirm that this study was conducted in accordance with the Declaration of Helsinki. All queries regarding related data sets collected and analyzed in the present study can be addressed to the corresponding author.

\section{Patients}

Patients with fresh thoracolumbar vertebral compression fractures referred to our institute from January 2014 to January 2016 were included in this prospective study. Inclusion criteria are: (i) older than 50 years old; (ii) refractory back pain caused by low-trauma damage after conservative treatment for at least 6 weeks; (iii) definite diagnosis of fresh thoracolumbar vertebral compression fracture through MRI or radionuclide bone scan; (iv) single vertebra fracture. Exclusion criteria are: (i) unstable vertebral compression fracture; (ii) malignant tumor; (iii) neurologic symptoms due to compression and stimulation to spinal marrow or nerve root; (iv) primary disease unable to tolerate the operation. It included patients who met the requirements in the study based on the voluntary principle. All included patients needed to sign informed consent forms. All included patients were randomly divided into three groups (group A, group B and group C).

\section{Surgical Technique}

The operation was performed through unilateral pedicle approach under local anesthesia. All the operative processes were directed under X-ray fluoroscopy. The patients in group A and B were operated on following the procedures outlined below (Figure 1). After a working cannula was established in the vertebral body, a VBS system (Weigao Group Co Ltd, CHN) was propped up through the balloon to restore the vertebral body height. Then, 


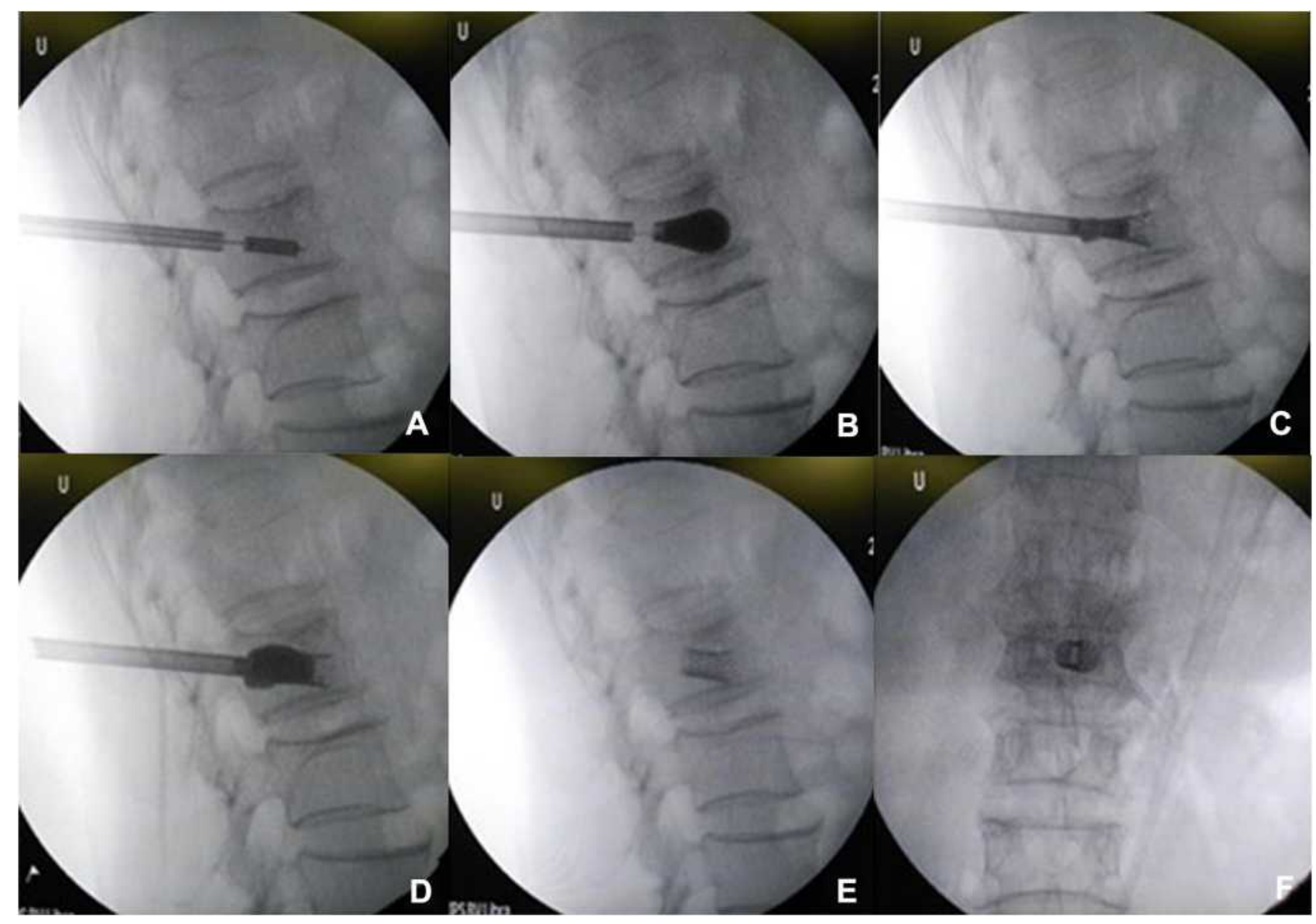

Figure I Intraoperative radiological images. (A) Build a working cannula through unilateral pedicle approach. (B) Inflate balloon and push open VBS. (C and D) Adjust the balloon placement and completely push open VBS. (E and F) Remove balloon and inject filler material, then remove working cannula.

Abbreviation: VBS, vertebral body stenting.

bone filler was injected into the vertebral body after the balloon was removed. The patients in group A were injected with CSCP fillers (Gene-X, Biocomposites Ltd, $\mathrm{UK}$ ), while patients in group B with $\mathrm{HAP} / \mathrm{COL}$ composite filler (Bongold, Beijing Allgens Medical Science \& Technology Co Ltd, CHN). Then, the working cannula was removed and skin was sutured. The patients in group $\mathrm{C}$ had traditional BKP filled with PMMA. All patients were inquired about the sensation and movement of the lower extremities immediately after surgery.

\section{Clinical and Radiological Evaluation}

Clinical evaluation was implemented through visual analogue pain scale (VAS) and Oswestry disability score (ODI). VAS was used to assess back pain $(0-10,0=$ no pain, $10=$ worst pain). Meanwhile, ODI was investigated to evaluate disability and the quality of life (ODI: the actual score/highest possible score $\times 100 \%, 0=$ normal, the closer to $100 \%$, the more serious the dysfunction is).
The operation time, blood loss, bone filler volume and complications were recorded and evaluated. Radiological evaluation was measured by the vertebral height and Cobb angle of the operative vertebra on the lateral radiograph. Cobb angle was measured between superior and inferior endplate of operative vertebrae. Vertebral height compression rate was calculated by a ratio of anterior to posterior height. The osteogenesis was evaluated from transverse section computed tomography (CT) images. Three circular areas $\left(2 \mathrm{~mm}^{2}\right)$ inside the VBS were randomly selected to calculate average $\mathrm{CT}$ value (Hounsfield unit, $\mathrm{Hu}$ ). Three circular areas $\left(2 \mathrm{~mm}^{2}\right)$ randomly selected outside the VBS in the same vertebra were considered as the standard control. The CT values comparison between inside and outside of the VBS and the observation of bone trabecula were applied as the osteogenesis evaluation method. All the above data were collected and recorded preoperatively, 1 day after surgery, 1 year after surgery (short term) and 3 years (long term) after surgery. 


\section{Statistical Analysis}

All statistical analysis was conducted in SPSS 20.0. The age, body height, body weight, BMI, BMD, VAS, ODI, $\mathrm{AH}$, preoperative $\mathrm{Cobb}$ angle, preoperative compression rate, intraoperative blood loss, operation time and bone fillers volume were shown as average \pm standard deviation. Paired $t$-test was used for comparison within the group. One-way ANOVA test was used for comparison between the three groups. Chi-square test was used for comparison of the sexual distribution of the three groups. $\mathrm{P}<0.05$ was considered as statistically significant.

\section{Results}

The 42 patients included in the study were randomly divided into three groups (14 patients per group). All patients went through surgeries successfully. Mean followup time was 3 years. There was no significant difference in age, gender, body height, weight, BMI, BMD, preoperative Cobb angle, preoperative compression rate, intraoperative blood loss, operation time and bone filler volume in the three groups (Table 1).

The preoperative VAS showed a mean score of 7.71 \pm 0.61 in group A, 7.71 \pm 0.67 in group B and 7.39 \pm 0.81 in group $\mathrm{C}$. The postoperative VAS evidently decreased to $2.39 \pm 0.45$ in group A, $1.86 \pm 0.63$ in group B and 2.07 \pm 0.51 in group $\mathrm{C}(\mathrm{P}<0.05)$. At 1 -year follow-up, VAS was maintained to $1.82 \pm 0.37$ in group $A, 1.75 \pm 0.58$ in group $\mathrm{B}$ and $1.79 \pm 0.58$ in group $\mathrm{C}$. The 3 -year VAS was 2.14 \pm 0.53 in group $A, 1.93 \pm 0.65$ in group $B$ and $1.68 \pm 0.61$ in group C. There was no significant difference in VAS among the three groups preoperatively and at each postoperative time point (Figure 2).

The preoperative assessment of ODI showed a mean score of $81.79 \pm 5.03$ in group $A, 81.36 \pm 4.36$ in group $\mathrm{B}$ and $79.93 \pm 4.76$ in group $\mathrm{C}$. There was no significant difference in ODI among the three groups before surgery. The postoperative ODI scores decreased to $36.79 \pm 5.26$ in group $\mathrm{A}, 34.0 \pm 4.80$ in group $\mathrm{B}$ and $32.71 \pm 3.81$ in group $\mathrm{C}(\mathrm{P}<0.05)$. At 1-year follow-up, the scores dropped to $21.48 \pm 4.68$ in group A, 23.64 \pm 4.92 in group B and 26.64 \pm 4.53 in group C. At 3-year follow-up, the scores remained $22.21 \pm 6.18$ in group $A, 19.36 \pm 7.32$ in group $B$ and $23.21 \pm 5.89$ in group C. There was no significant difference in ODI among the three groups at each postoperative time point (Figure 2).

As shown in Table 2, the AH and Cobb angle significantly improved compared with preoperative in three groups $(\mathrm{P}<0.05)$. Meanwhile, there was no significant difference among the three groups at preoperative and each postoperative time point (Figure 2). However, the $\mathrm{AH}$ was remarkably reduced from postoperative $(2.46$ $\pm 0.62 \mathrm{~cm})$ to 1 -year $(2.40 \pm 0.62 \mathrm{~cm})$ in group A $(\mathrm{P}=$ $0.005)$ and from postoperative $(2.49 \pm 0.62 \mathrm{~cm})$ to 1 -year $(2.40 \pm 0.54 \mathrm{~cm})$ in group $\mathrm{B}(\mathrm{P}=0.029)$. Both group A and group $\mathrm{B}$ presented loss of $\mathrm{AH}$ in the comparison within the group at 1-year follow-up. At 3-year follow-up, the loss of $\mathrm{AH}$ did not continue compared with 1-year follow-up, and was still higher than preoperative $(\mathrm{P}<0.05)$. A typical case

Table I Clinical Data Comparison in Three Groups

\begin{tabular}{|c|c|c|c|c|}
\hline & Group A & Group B & Group C & P-value \\
\hline Patient, n & 14 & 14 & 14 & I \\
\hline Mean age, y & $67.93 \pm 10.22$ & $65.7 I \pm I I .90$ & $68.21 \pm 8.45$ & 0.782 \\
\hline Sex, No. F:M & $8: 6$ & $8: 6$ & $9: 5$ & 0.906 \\
\hline Mean height, m & $1.66 \pm 0.08$ & $1.66 \pm 0.07$ & $1.63 \pm 0.06$ & 0.550 \\
\hline Mean weight, kg & $65.5 \pm 7.47$ & $66.36 \pm 7.75$ & $64.78 \pm 7.00$ & 0.919 \\
\hline Mean BMI, kg/m² & $23.70 \pm 1.25$ & $23.14 \pm 1.43$ & $24.11 \pm 1.88$ & 0.257 \\
\hline Lumbar BDM, SD & $-2.21 \pm 0.72$ & $-1.99 \pm 0.96$ & $-2.15 \pm 0.80$ & 0.771 \\
\hline Hip total BMD, SD & $-2.3 I \pm 0.74$ & $-2.16 \pm 0.80$ & $-2.13 \pm 0.73$ & 0.812 \\
\hline Cobb angle & $16.72 \pm 10.45$ & $15.74 \pm 9.68$ & $12.54 \pm 5.85$ & 0.438 \\
\hline Compression rate, $\%$ & $79.44 \pm 16.44$ & $77.03 \pm 14.90$ & $76.07 \pm 9.77$ & 0.807 \\
\hline Bone filler volume*, $\mathrm{mL}$ & $3.69 \pm 0.43$ & $3.78 \pm 0.35$ & $4.04 \pm 0.54$ & 0.121 \\
\hline Blood loss*, mL & $6.18 \pm 0.91$ & $6.64 \pm 0.99$ & $7.03 \pm 1.39$ & 0.141 \\
\hline Operation time*, min & $35.7 I \pm 5.00$ & $37.64 \pm 5.44$ & $36.57 \pm 7.05$ & 0.690 \\
\hline Filler leakage $\mathrm{e}^{\#}$ & I & 0 & 2 & 0.231 \\
\hline Adjacent vertebra fracture $^{\#}$ & 0 & 0 & 1 & 0.325 \\
\hline
\end{tabular}

Notes: *Indicates intraoperative data. ${ }^{\#}$ Indicates postoperative data. 

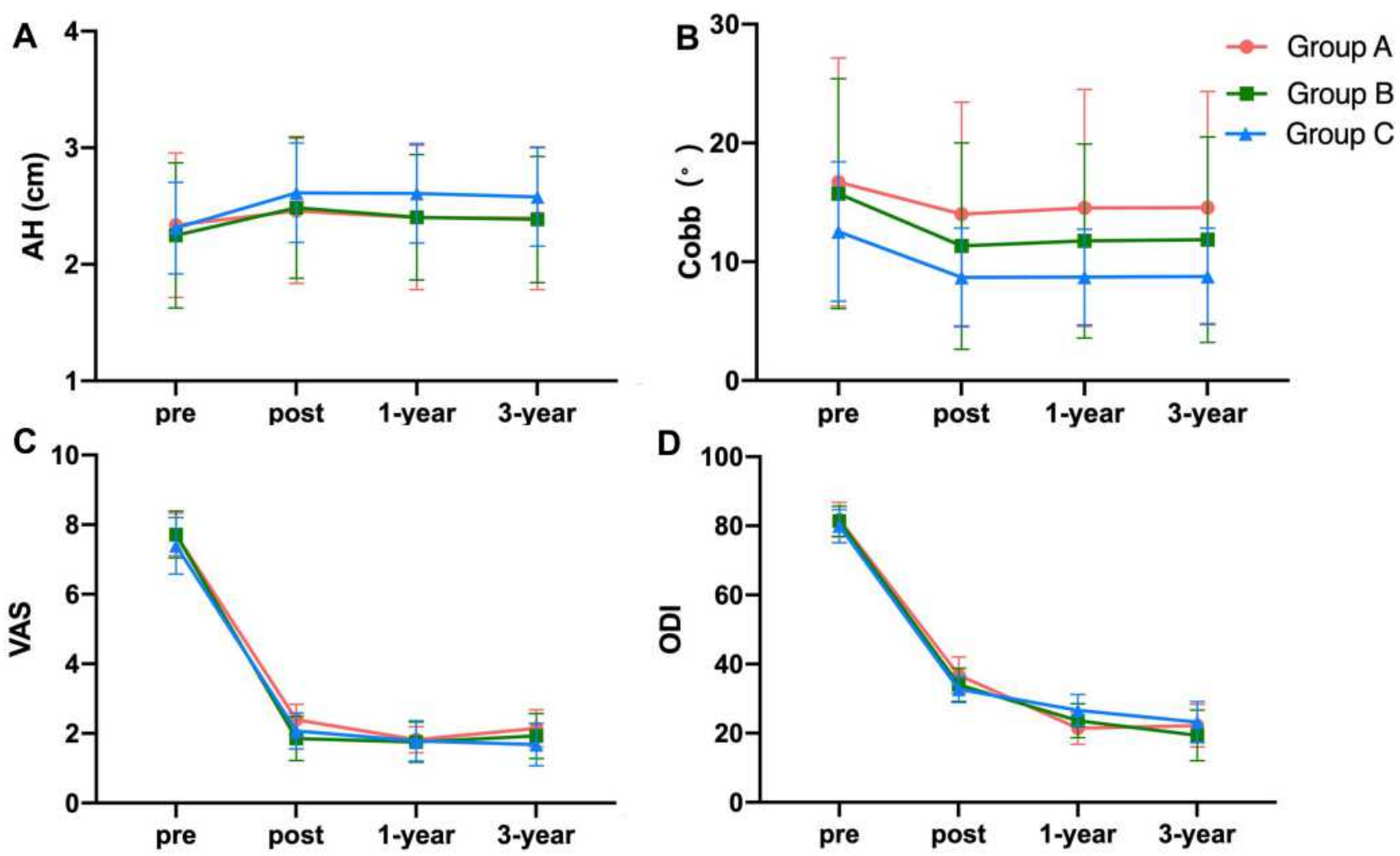

Figure 2 The clinical and radiological evaluation indicators trend. Three groups were not significantly different from each other for each evaluation indicator preoperatively and at each postoperative follow-up point (P>0.05). (A) AH. (B) Cobb angle. (C) VAS. (D) ODI.

Abbreviations: AH, anterior height; VAS, visual analogue scale; ODI, Oswestry disability score.

of vertebral height loss during the follow-up is presented in Figure 3.

As to the osteogenesis efficacy of fillers, we could observe remarkable bone trabecula formation from the transverse section CT images in group A and group B at 1-year and 3-year follow-up (Figure 4). In group A, the CT value inside the VBS was gradually dropping, but always higher than outside the VBS with the time prolongation. The CT value in the group B was gradually rising and higher than outside the VBS at 1-year follow-up (Table 3). After 1 year, the CT value inside the VBS was higher than the control area in group A and group $\mathrm{B}(\mathrm{P}<0.05)$.
Two patients in group $\mathrm{C}$ and one in group $\mathrm{A}$ experienced asymptomatic cement leakage. One patient suffered adjacent vertebral body fracture in group C (Table 1). No complications such as nerve root compression, spinal cord compression, pulmonary embolism, fat embolism, thrombus or wound infection were observed in the three groups.

\section{Discussion}

VP and BKP are the most common minimally invasive treatments for patients with vertebral compression fractures. Both techniques can relieve pain and improve the quality of life. Our clinical data show that stentoplasty

Table 2 The Radiological Data Preoperatively and at Each Postoperative Time Point

\begin{tabular}{|c|c|c|c|c|c|c|}
\hline \multirow[t]{2}{*}{ Time } & \multicolumn{2}{|c|}{ Group A } & \multicolumn{2}{|c|}{ Group B } & \multicolumn{2}{|c|}{ Group C } \\
\hline & $\mathbf{A H}$ & Cobb & AH & Cobb & $\mathbf{A H}$ & Cobb \\
\hline Preoperative & $2.34 \pm 0.62$ & $16.72 \pm 10.45$ & $2.25 \pm 0.62$ & $15.74 \pm 9.68$ & $2.31 \pm 0.39$ & $12.55 \pm 5.85$ \\
\hline Postoperative & $2.46 \pm 0.62 *$ & $|4.0| \pm\left. 9.4\right|^{*}$ & $2.49 \pm 0.62^{*}$ & II. $33 \pm 8.69 *$ & $2.61 \pm 0.43^{*}$ & $8.69 \pm 4.15^{*}$ \\
\hline I-year & $2.40 \pm 0.62^{* \#}$ & $14.54 \pm 9.97 *$ & $2.40 \pm 0.54^{* \#}$ & I I. $87 \pm 8.65^{*}$ & $2.61 \pm 0.43^{*}$ & $8.7 I \pm 4.02 *$ \\
\hline 3-year & $2.40 \pm 0.6 \mathrm{I}^{* \#}$ & $14.57 \pm 9.76 *$ & $2.39 \pm 0.54 * \#$ & $11.78 \pm 8.17^{*}$ & $2.58 \pm 0.42^{*}$ & $8.76 \pm 4.06 *$ \\
\hline
\end{tabular}

Notes: ${ }^{*} \mathrm{P}<0.05$ vs preoperative values; ${ }^{*} \mathrm{P}<0.05$ vs postoperative values.

Abbreviations: $\mathrm{AH}$, anterior height. 


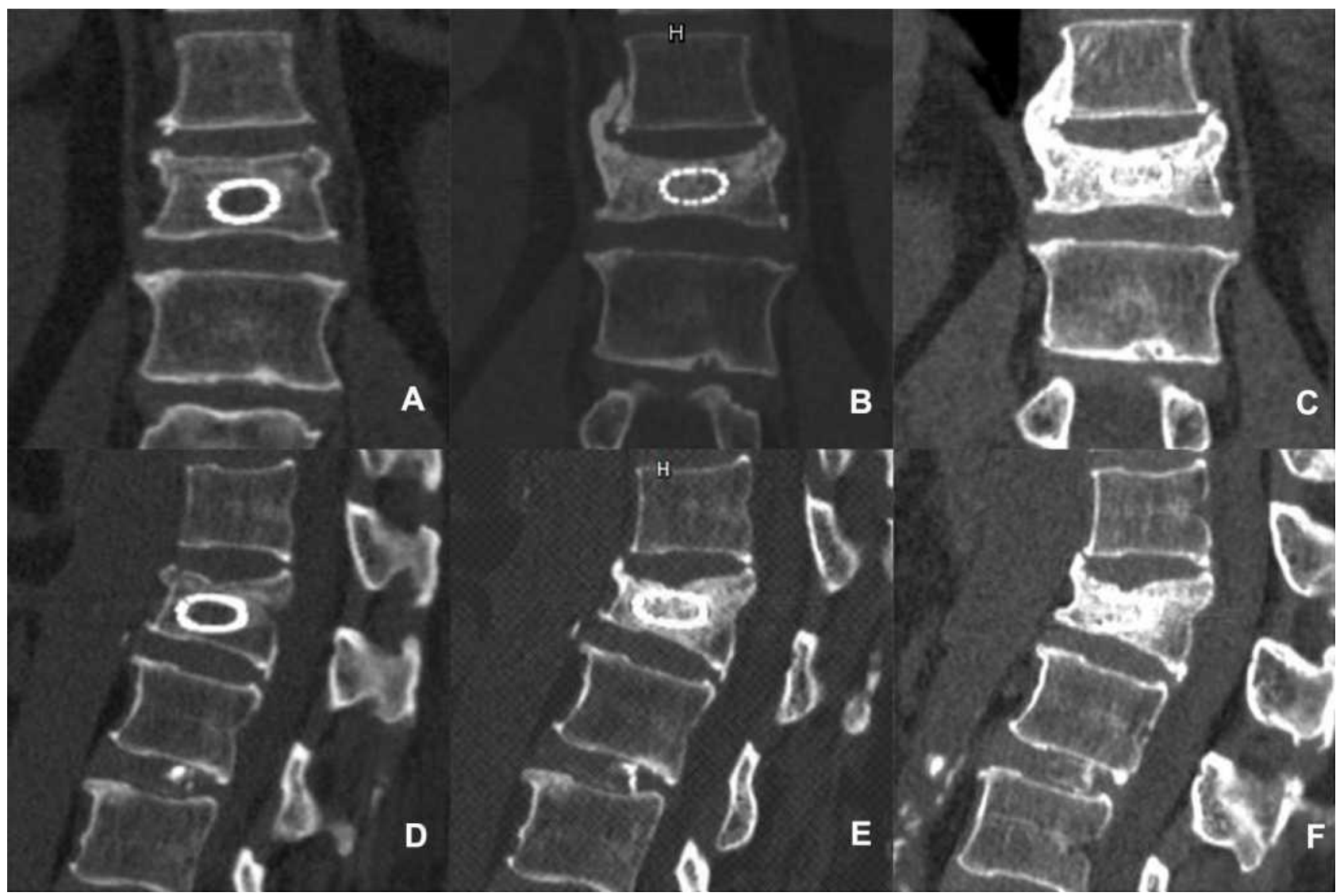

Figure 3 A typical case of vertebral height (LI) loss during the follow-up. (A) Coronal image at I day after operation. (B) Coronal image at I year after operation. (C) Coronal image at 3 years after operation. (D) Sagittal image at I day after operation. (E) Sagittal image at I year after operation. (F) Sagittal image at 3 years after operation.

with resorbable bone fillers also has an outstanding contribution to relieve back pain and improve quality of life. The postoperative VAS and ODI scores improved evidently compared with their preoperative values. At each follow-up time, the VAS and ODI were maintained within satisfactory levels after operation. Both in the short term and long term, this operation played an important role in pain relief and quality of life improvement. In this study, we reported for the first time the similar clinical efficacy between stentoplasty with resorbable bone fillers and BKP with PMMA. This result can help better understanding of the mechanism of BKP pain reduction. Some authors insisted that sensory nerve ending fibers can be destroyed through polymerization heat reaction and monomer toxicity of PMMA. ${ }^{18}$ However, resorbable bone fillers did not produce any heat or toxic substance that influenced sensory nerve ending fibers. Therefore, the stabilization of vertebra is the critical factor for immediate and persistent pain alleviation. Mechanical stabilization can prevent stimulation of algesi receptors in the periosteum, bone marrow and Haversian system.
VBS can effectively restore and maintain the vertebral height, and has been widely used in the treatment of vertebral fractures. ${ }^{22,27}$ Restoration of the vertebral body height can reduce the stresses on the adjacent endplates and decrease the risk of refracture. ${ }^{28}$ In our study, postoperative vertebral height and Cobb angle were obviously improved. However, the AH of the vertebral body appeared to have a slight loss within 1 year, but was still higher than preoperatively. At present, the strength of resorbable bone fillers is far weaker than that of PMMA. VBS with bone fillers cannot provide enough strength to support a routine load before formation of actual bone architecture. After bone structure is reconstituted, the vertebral height is kept relatively stable with a higher strength which prompts secondary stabilization. Therefore, the height did not change from 1-year to 3-year.

In this study, two types of resorbable bone fillers significantly enhanced bone cancellous reconstruction of the vertebral body. In fact, two types of bone fillers prompt osteogenesis with different mechanisms. CSCP is a composite material composed of calcium sulfate and 


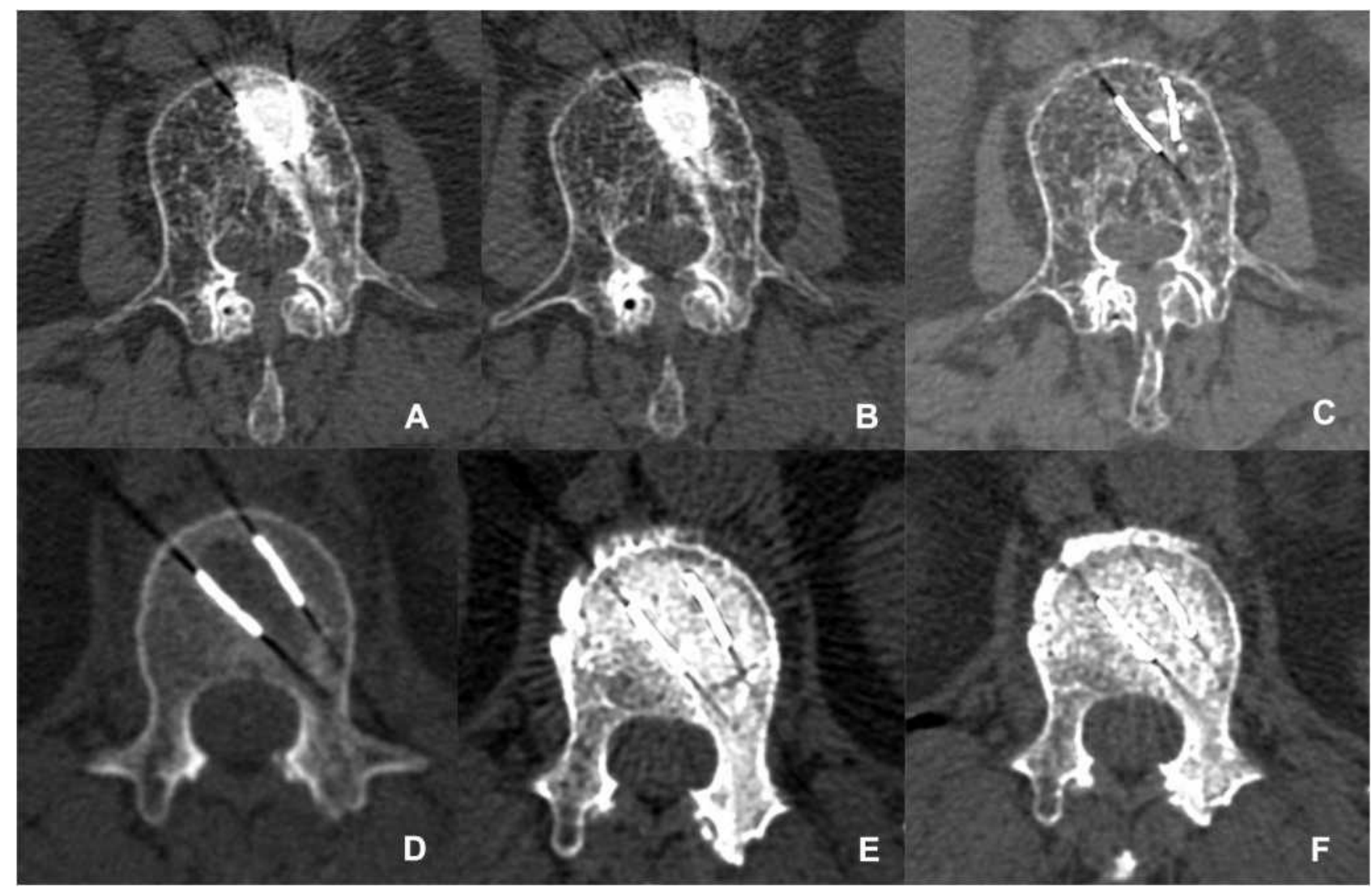

Figure 4 The evaluation of bone trabecula formation and density variation inside and outside the VBS at I day, I year and 3 years after operation. (A-C) Group A. (D-F). Group B.

calcium phosphate based on a certain ratio, which has been used in clinics for several years. ${ }^{29}$ The resorption of CSCP is accompanied with vascular infiltration, osteoid deposition and finally restoration of new mineralized bone trabeculae. ${ }^{30}$ In addition, it has been shown that CSCP composite can stimulate cell proliferation and enhance angiogenesis, which can be directly bonded to host bone. In a rabbit femur model, CSCP can repair the defect with newly formed bone at 6 months. ${ }^{31}$ In our previous study, we reported prophylactic VP with CSCP in sandwich vertebrae. The 2-year follow-up study result showed prophylactic VP with CSCP decreased the fracture risk of sandwich vertebrae. ${ }^{23} \mathrm{HAP} / \mathrm{COL}$ composite is composed of type I collagen fiber and hydroxyapatite nanocrystals, which is like that of natural bone. ${ }^{32,33}$ Moreover, the porous structure provides effective space for bone formation not only around the fillers but also into their pores. The open porous structures both allow cells to migrate into the fillers and blood vessels to grow into material, which provides the oxygen and nutrition for osteogenesis. ${ }^{34,35}$ In a rabbit tibial model, bone defect was transplanted with $\mathrm{HAP} / \mathrm{COL}$ composite. Bone defects were repaired and matured at 2 months and fillers were fully resorbed in the bone marrow cavities at 3 months. ${ }^{36}$ Feng et al. studied

Table 3 The CT Value of Inside and Outside VSB at Each Postoperative Time Point

\begin{tabular}{|c|c|c|c|c|c|c|}
\hline & \multicolumn{3}{|c|}{ Group A } & \multicolumn{3}{|c|}{ Group B } \\
\hline & VBS & Control & $\mathbf{P}$ & VBS & Control & $\mathbf{P}$ \\
\hline Postoperative & $336.7 I \pm 4 I .70$ & $62.29 \pm 8.48$ & $<0.01$ & $52.21 \pm 9.96$ & $61.71 \pm 6.35$ & $<0.01$ \\
\hline I year & $233.14 \pm 32.45^{*}$ & $61.07 \pm 10.00$ & $<0.01$ & $146.79 \pm 16.78^{*}$ & $61.21 \pm 13.80$ & $<0.01$ \\
\hline 3 years & $136.21 \pm 40.15^{* \#}$ & $62.85 \pm 14.16$ & $<0.01$ & $139.14 \pm 19.04 * \#$ & $63.36 \pm 11.98$ & $<0.01$ \\
\hline
\end{tabular}

Notes: ${ }^{*} \mathrm{P}<0.05$ vs postoperative values; ${ }^{\#} \mathrm{P}<0.05$ vs I year after surgery values. 
the application of $\mathrm{HAP} / \mathrm{COL}$ in human extraction sockets and analyzed height of new bone formation. They concluded that mineralized HAP/COL has better osteogenesis compared with ordinary and has broad clinical application prospects. $^{37}$

In our study, CSCP and HAP/COL have good osteogenesis effect based on CT observation. Actually, CSCP and HAP/COL presented different density change trends in the process of osteogenesis. The density of CSCP area gradually decreased with fillers resorption and new bone formation. ${ }^{38}$ However, HAP/COL presented low density at the beginning of implantation and increased with the calcium salt deposition. Therefore, the osteogenesis effect cannot be directly compared between CSCP and HAP/ COL by CT values.

Most studies reported that the risk of adjacent vertebrae fracture increased because of higher stiffness of PMMA. ${ }^{39,40}$ Ottardi et al. reported that effective restoration of vertebral height can reduce adjacent vertebrae fracture incidence. ${ }^{28}$ The rate of adjacent vertebrae fracture in our study did not show significant differences, which may be associated with consistent vertebral height. So far, it is not clear about the stiffness of VBS compared with PMMA. Cement leakage is the most common complication of vertebral augmentation. ${ }^{41}$ In our study, two patients in the PMMA group and one in the CSCP group were observed to have asymptomatic cement leakage through CT scan.

There are a few limitations to this study. First, the sample size is relatively small. Further studies may need to recruit more patients. Second, there is a lack of precise method to compare osteogenesis properties of these two kinds of fillers. Third, the wearing time of a waist brace has not been standardized, which could influence the changes of vertebral height in the early postoperative period.

\section{Conclusion}

The stentoplasty with resorbable calcium salt bone void fillers demonstrated similar clinical outcomes to traditional BKP for vertebral compression fractures. Both HAP/COL and CSCP have performed certain osteogenesis. However, stentoplasty with studied fillers exhibited slight loss of the AH within 1 year after surgery.

\section{Data Sharing Statement}

All requests for related data sets collected and analyzed in the present study can be addressed to the corresponding author.

\section{Ethics Approval and Consent to Participate}

This study was approved by the life ethics committee of Beijing Friendship Hospital and was registered in China clinical research and trial center (ChiCTR-OIC -16008922). We confirm that this study was conducted in accordance with the Declaration of Helsinki. All included patients needed to sign informed consent forms.

\section{Acknowledgment}

We are grateful to those who contributed to this article and your contributions helped us complete this article.

\section{Author Contributions}

All authors made substantial contributions to conception and design, acquisition of data, or analysis and interpretation of data; took part in drafting the article or revising it critically for important intellectual content; agreed to submit to the current journal; gave final approval of the version to be published; and agree to be accountable for all aspects of the work.

\section{Funding}

The vertebra bone stentings were supported from Shandong Weigao Group Limited Corporation.

\section{Disclosure}

Mengmeng Chen, Ruideng Wang, Pu Jia, Li Bao and Hai Tang declare that they have no conflicts of interest.

\section{References}

1. Galibert P, Deramond H, Rosat P, Le Gars D. [Preliminary note on the treatment of vertebral angioma by percutaneous acrylic vertebroplasty]. Neurochirurgie. 1987;33(2):166-168. Romanian.

2. Zhu SY, Zhong ZM, Wu Q, Chen JT. Risk factors for bone cement leakage in percutaneous vertebroplasty: a retrospective study of four hundred and eighty five patients. Int Orthop. 2016;40(6):1205-1210. doi:10.1007/s00264-015-3102-2

3. Yoo KY, Jeong SW, Yoon W, Lee J. Acute respiratory distress syndrome associated with pulmonary cement embolism following percutaneous vertebroplasty with polymethylmethacrylate. Spine (Phila Pa 1976). 2004;29(14):E294-E297. doi:10.1097/01.brs.0000131211.8 7594.b0

4. Grados F, Marcelli C, Dargent-Molina P, Roux C, Vergnol JF, Meunier PJ. Prevalence of vertebral fractures in French women older than 75 years from the EPIDOS study. Bone. 2004;34(2):362-367. doi:10.1016/j.bone.2003.11.008

5. Ma XL, Xing D, Ma JX, Xu WG, Wang J, Chen Y. Balloon kyphoplasty versus percutaneous vertebroplasty in treating osteoporotic vertebral compression fracture: grading the evidence through a systematic review and meta-analysis. Eur Spine J. 2012;21(9):1844-1859. doi:10.1007/s00586-012-2441-6 
6. Lovi A, Teli M, Ortolina A, Costa F, Fornari M, Brayda-Bruno M. Vertebroplasty and kyphoplasty: complementary techniques for the treatment of painful osteoporotic vertebral compression fractures. A prospective non-randomised study on 154 patients. Eur Spine J. 2009;18(Suppl 1):95-101. doi:10.1007/s00586-009-0986-9

7. Rotter R, Martin H, Fuerderer S, Gabl M, Roeder C, Heini P. Vertebral body stenting: a new method for vertebral augmentation versus kyphoplasty. Eur Spine J. 2010;19(6):916-923. doi:10.1007/ s00586-010-1341-x

8. Garnon J, Dore B, Auloge P, Caudrelier J, Dalili D, Ramamurthy N. Efficacy of the vertebral body stenting system for the restoration of vertebral height in acute traumatic compression fractures in a non-osteoporotic population. Cardiovasc Intervent Radiol. 2019;42 (11):1579-1587. doi:10.1007/s00270-019-02265-y

9. Distefano D, Scarone P, Isalberti M, La Barbera L, Villa T, Bonaldi G. The 'armed concrete' approach: stent-screw-assisted internal fixation (SAIF) reconstructs and internally fixates the most severe osteoporotic vertebral fractures. J Neurointerv Surg. 2021;13 (1):63-68. doi:10.1136/neurintsurg-2020-016597

10. Cianfoni A, Distefano D, Scarone P, Pesce GA, Espeli V, La Barbera L. Stent screw-assisted internal fixation (SAIF): clinical report of a novel approach to stabilizing and internally fixating vertebrae destroyed by malignancy. J Neurosurg Spine. 2019;1-12. doi:10.3171/2019.9.SPINE19711

11. La Barbera L, Cianfoni A, Ferrari A, Distefano D, Bonaldi G, Villa T. Stent Screw-Assisted Internal Fixation (SAIF) of severe lytic spinal metastases: a comparative finite element analysis of the SAIF technique. World Neurosurg. 2019;128:e370-e377. doi:10.1016/j. wneu.2019.04.154

12. La Barbera L, Cianfoni A, Ferrari A, Distefano D, Bonaldi G, Villa T. Stent-screw assisted internal fixation of osteoporotic vertebrae: a comparative finite element analysis on SAIF technique. Front Bioeng Biotechnol. 2019;7:291. doi:10.3389/fbioe.2019.00291

13. Nelson DA, Barker ME, Hamlin BH. Thermal effects of acrylic cementation at bone tumour sites. Int J Hyperthermia. 1997;13 (3):287-306. doi:10.3109/02656739709023537

14. Dahl OE, Garvik LJ, Lyberg T. Toxic effects of methylmethacrylate monomer on leukocytes and endothelial cells in vitro. Acta Orthop Scand. 1994;65(2):147-153. doi:10.3109/17453679408995423

15. Rho YJ, Choe WJ, Chun YI. Risk factors predicting the new symptomatic vertebral compression fractures after percutaneous vertebroplasty or kyphoplasty. Eur Spine J. 2012;21(5):905-911. doi:10.1007/s00586-011-2099-5

16. Hillmeier J, Meeder PJ, Noldge G, Kock HJ, Da Fonseca K, Kasperk HC. [Balloon kyphoplasty of vertebral compression fractures with a new calcium phosphate cement]. Orthopade. 2004;33 (1):31-39. German. doi:10.1007/s00132-003-0578-z

17. Maestretti G, Cremer C, Otten P, Jakob RP. Prospective study of standalone balloon kyphoplasty with calcium phosphate cement augmentation in traumatic fractures. Eur Spine J. 2007;16(5):601-610. doi:10.1007/s00586-006-0258-x

18. Grafe IA, Baier M, Noldge G, Weiss C, Da Fonseca K, Hillmeier J. Calcium-phosphate and polymethylmethacrylate cement in long-term outcome after kyphoplasty of painful osteoporotic vertebral fractures. Spine (Phila Pa 1976). 2008;33(11):1284-1290. doi:10.1097/ BRS.0b013e3181714a84

19. Piazzolla A, De Giorgi G, Solarino G. Vertebral body recollapse without trauma after kyphoplasty with calcium phosphate cement. Musculoskelet Surg. 2011;95(2):141-145. doi:10.1007/s12306-0110130-y

20. Heo DH, Kuh SU. Progressive, repeated lumbar compression fracture at the same level after vertebral kyphoplasty with calcium phosphate cement. Case report. J Neurosurg Spine. 2007;6(6):559-562. doi:10.3171/spi.2007.6.6.7
21. Blattert TR, Jestaedt L, Weckbach A. Suitability of a calcium phosphate cement in osteoporotic vertebral body fracture augmentation: a controlled, randomized, clinical trial of balloon kyphoplasty comparing calcium phosphate versus polymethylmethacrylate. Spine (Phila Pa 1976). 2009;34(2):108-114. doi:10.1097/ BRS.0b013e31818f8bc1

22. Schutzenberger S, Schwarz SM, Greiner L, Holub O, Grabner S, Huf W. Is vertebral body stenting in combination with $\mathrm{CaP}$ cement superior to kyphoplasty? Eur Spine J. 2018;27(10):2602-2608. doi:10.1007/s00586-018-5717-7

23. Jia P, Tang H, Chen H, Bao L, Feng F, Yang H. Prophylactic vertebroplasty procedure applied with a resorbable bone cement can decrease the fracture risk of sandwich vertebrae: long-term evaluation of clinical outcomes. Regen Biomater. 2017;4(1):47-53. doi:10.1093/ rb/rbw037

24. Smeets R, Kolk A, Gerressen M, Driemel O, Maciejewski O, Hermanns-Sachweh B. A new biphasic osteoinductive calcium composite material with a negative Zeta potential for bone augmentation. Head Face Med. 2009;5:13. doi:10.1186/1746-160X-5-13

25. Miron RJ, Zhang Q, Sculean A, Buser D, Pippenger BE, Dard M. Osteoinductive potential of 4 commonly employed bone grafts. Clin Oral Investig. 2016;20(8):2259-2265. doi:10.1007/s00784-0161724-4

26. Rh Owen G, Dard M, Larjava H. Hydoxyapatite/beta-tricalcium phosphate biphasic ceramics as regenerative material for the repair of complex bone defects. J Biomed Mater Res B Appl Biomater. 2018;106(6):2493-2512. doi:10.1002/jbm.b.34049

27. Hartmann F, Griese M, Dietz SO, Kuhn S, Rommens PM, Gercek E. Two-year results of vertebral body stenting for the treatment of traumatic incomplete burst fractures. Minim Invasive Ther Allied Technol. 2015;24(3):161-166. doi:10.3109/13645706.2014.962546

28. Ottardi C, La Barbera L, Pietrogrande L, Villa T. Vertebroplasty and kyphoplasty for the treatment of thoracic fractures in osteoporotic patients: a finite element comparative analysis. J Appl Biomater Funct Mater. 2016;14(2):e197-204. doi:10.5301/jabfm.5000287

29. Urban RM, Turner TM, Hall DJ, Inoue N, Gitelis S. Increased bone formation using calcium sulfate-calcium phosphate composite graft. Clin Orthop Relat Res. 2007;459:110-117. doi:10.1097/ BLO.0b013e318059b902

30. Walsh WR, Morberg P, Yu Y, Yang JL, Haggard W, Sheath PC. Response of a calcium sulfate bone graft substitute in a confined cancellous defect. Clin Orthop Relat Res. 2003;406(406):228-236. doi:10.1097/00003086-200301000-00033

31. Hu G, Xiao L, Fu H, Bi D, Ma H, Tong P. Study on injectable and degradable cement of calcium sulphate and calcium phosphate for bone repair. J Mater Sci Mater Med. 2010;21(2):627-634. doi:10.1007/s10856-009-3885-z

32. Du C, Cui FZ, Zhang W, Feng QL, Zhu XD, de Groot K. Formation of calcium phosphate/collagen composites through mineralization of collagen matrix. J Biomed Mater Res. 2000;50(4):518-527. doi:10.1002/(sici)1097-4636(20000615)50:4<518::aid-jbm7>3.0. co;2-w

33. Kikuchi M, Itoh S, Ichinose S, Shinomiya K, Tanaka J. Selforganization mechanism in a bone-like hydroxyapatite/collagen nanocomposite synthesized in vitro and its biological reaction in vivo. Biomaterials. 2001;22(13):1705-1711. doi:10.1016/s0142-9612(00) 00305-7

34. Karageorgiou V, Kaplan D. Porosity of 3D biomaterial scaffolds and osteogenesis. Biomaterials. 2005;26(27):5474-5491. doi:10.1016/j. biomaterials.2005.02.002

35. Wang S, Yang Y, Koons GL, Mikos AG, Qiu Z, Song T. Tuning pore features of mineralized collagen/PCL scaffolds for cranial bone regeneration in a rat model. Mater Sci Eng C Mater Biol Appl. 2020;106:110186. doi:10.1016/j.msec.2019.110186 
36. Tsuchiya A, Sotome S, Asou Y, Kikuchi M, Koyama Y, Ogawa T. Effects of pore size and implant volume of porous hydroxyapatite/ collagen $(\mathrm{HAp} / \mathrm{Col})$ on bone formation in a rabbit bone defect model. $J$ Med Dent Sci. 2008;55(1):91-99.

37. Feng L, Zhang L, Cui Y, Song TX, Qiu ZY, Wang XM. Clinical evaluations of mineralized collagen in the extraction sites preservation. Regen Biomater. 2016;3(1):41-48. doi:10.1093/rb/ rbv027

38. Civinini R, Capone A, Carulli C, Matassi F, Nistri L, Innocenti M. The kinetics of remodeling of a calcium sulfate/calcium phosphate bioceramic. J Mater Sci Mater Med. 2017;28(9):137. doi:10.1007/ s10856-017-5940-5
39. Berlemann U, Ferguson SJ, Nolte LP, Heini PF. Adjacent vertebral failure after vertebroplasty. A biomechanical investigation. $J$ Bone Joint Surg Br. 2002;84-B(5):748-752. doi:10.1302/0301620X.84B5.0840748

40. Polikeit A, Nolte LP, Ferguson SJ. The effect of cement augmentation on the load transfer in an osteoporotic functional spinal unit: finite-element analysis. Spine (Phila Pa 1976). 2003;28 (10):991-996. doi:10.1097/01.BRS.0000061987.71624.17

41. Elnoamany H. Percutaneous vertebroplasty: a first line treatment in traumatic non-osteoporotic vertebral compression fractures. Asian Spine J. 2015;9(2):178-184. doi:10.4184/asj.2015.9.2.178

\section{Publish your work in this journal}

Clinical Interventions in Aging is an international, peer-reviewed journal focusing on evidence-based reports on the value or lack thereof of treatments intended to prevent or delay the onset of maladaptive correlates of aging in human beings. This journal is indexed on PubMed Central, MedLine, CAS, Scopus and the Elsevier
Bibliographic databases. The manuscript management system is completely online and includes a very quick and fair peer-review system, which is all easy to use. Visit http://www.dovepress.com/ testimonials.php to read real quotes from published authors. 